\title{
Hamartomatosis polyposis: Peutz-jeghers syndrome: case report and review of the literature
}

\begin{abstract}
Peutz-jeghers syndrome is a rare inherited disorder with autosomal dominant transmission that manifests primarily as peri-orificial cutaneous-mucous lentiginosis and gastrointestinal hamartomatous polyps with the possibility of other locations in the lungs and reproductive organs. The main complications are gastrointestinal bleeding, bowel obstruction and rectal prolapse. This disease is associated with a high risk of malignant degeneration not only digestive but also pulmonary, mammary, testicular hence the need for a regular long-term codified monitoring. The treatment is most often conservative especially in children in growth period.
\end{abstract}

Keywords: Peutz-Jeghers syndrome, hamartomatous polyps, digestive cancers
Volume 12 Issue 3 - 202 I

\author{
Bouchrit Sara, Roudi S, Kouwakanou B, Ait \\ Errami A, Oubaha S, Samlani Z, Krati K \\ Department of Gastroenterology, Mohammed VI University \\ Hospital Center, Morocco
}

\begin{abstract}
Correspondence: Bouchrit S, Department of
Gastroenterology, Mohammed VI University Hospital Center, Morocco, Email sarah.bouchrit2@gmail.com
\end{abstract}

Received: March 09, 2021 | Published: June 21, 2021

\section{Introduction}

Peutz-Jeghers syndrome (PJS) is an inherited disorder with autosomal dominant transmission, the main manifestations of which are gastrointestinal hamartomatous polyposis and peri-orificial pigmented skin-mucous lesions. The gene called STK11 has recently been identified to cause this condition. PJS is accompanied by an increased risk of cancer in a hamartoma-dysplasia-cancer sequence. Through this publication, we report a case of PJS in a young person revealed by chronic abdominal pain and digestive hemorrhage (melena) and in the light of the literature we well treat the characteristics and complications of this genetic entity.

\section{Case report}

A 16-year-old youngster, with no particular pathological history, in particular no history of familial polyposis or of personal or family digestive or extra-digestive neoplasia, admitted to the gastroenterology department for etiological assessment of chronic intermittent abdominal pain with episodes of melena, without transit disorders evolving in a context of conservation of general condition.

On clinical examination, the abdomen is supple, with slight tenderness on palpation without palpable mass or impasto and pigmented cheek macules.

An endoscopic exploration was carried out objectifying:

I. On eso-gastro-duodenal fibroscopy: erythematous petechial gastric mucosa with multiple polyps of different ages and sizes, the largest of which are around $1 \mathrm{~cm}$, biopsies were taken (Figure 1).

II. At colonoscopy: progression to low coecal with catheterization of the last ileal loop, presence of several polyps of different size all over the colon and the last ileal loop, the largest of which is located at the right colon measuring approximately $3 \mathrm{~cm}$ pedunculated, biopsies were performed on the polyp and on the ileo-colic mucosa (Figures $2 \& 3$ ).

The anatomopathological study concluded that there was an inflammatory change in hamartomatous polyps which could be considered as a Peutz-jeghers syndrome. Absence of histological signs of malignancy.Our patient was included in the monitoring protocol with a fibroscopy and colonoscopy every 2 years, a testicular ultrasound and a CT enteric scan to explore the small intestine by lack of means for the video-capsule.

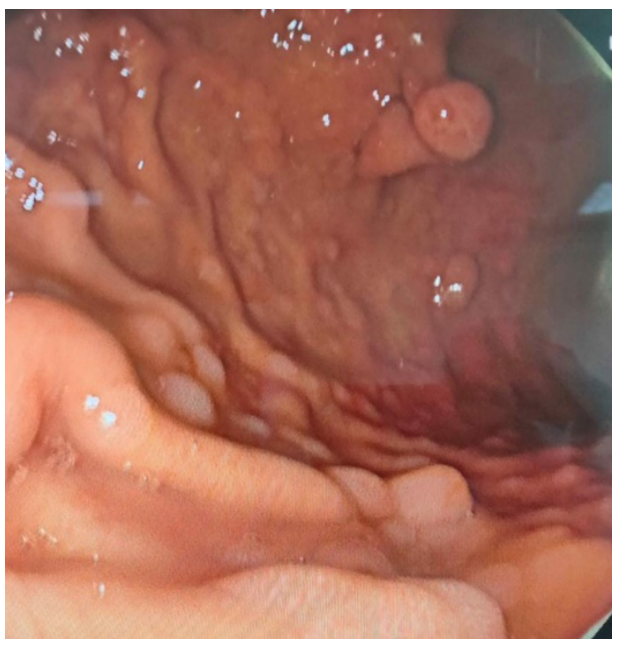

Figure I Gastric polyps.

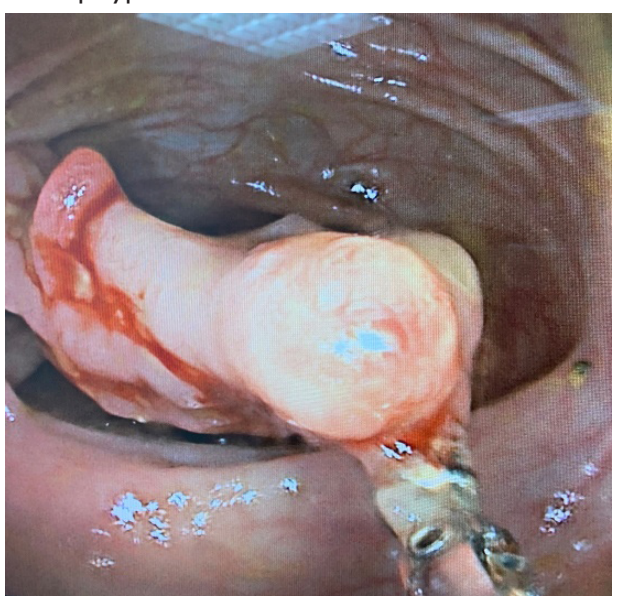

Figure 2 Pedicled colonic polyp. 


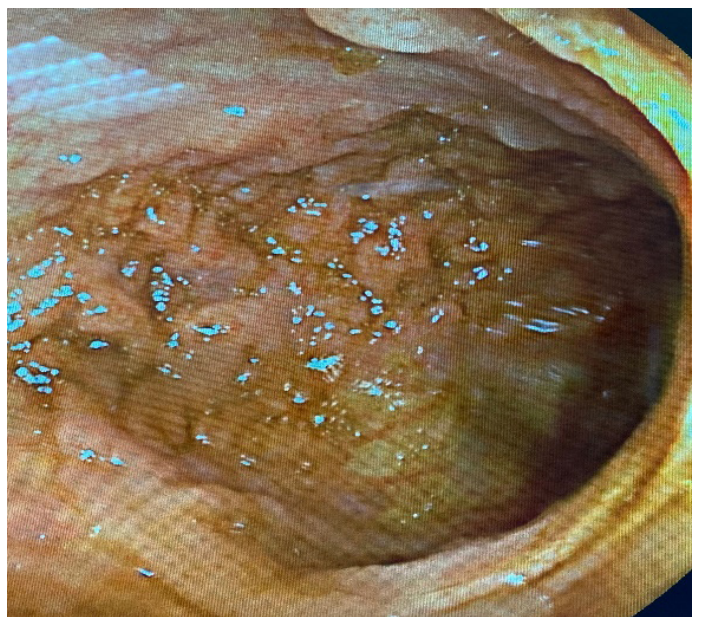

Figure 3 Polyps of the last ileal loop.

\section{Discussion}

Peutz-jeghers syndrome characterized by the association of periorificial lentiginosis-like skin involvement (nose, lips, anal and genital areas), digestive, pulmonary and reproductive organ involvement. The prevalence is estimated at $1 / 200,000$, without predominance of sex or race, in a review of 75 cases the age of diagnosis is 22 years. ${ }^{1}$

The first report made in 1921 by Jan Peutz who reported the case of a family with gastrointestinal polyposis and cutaneous-mucous lentiginosis. ${ }^{2}$ In 1949, Joseph Jeghers reported cases of patients with intestinal polyposis and skin pigmentation, which led to the identification of the syndrome named after the two doctors. ${ }^{2,3,4}$ This syndrome is linked to a mutation in the tumor suppressor gene LKB1STK11 (19p13.3) in 30 to $80 \%$ of cases. This gene codes for a protein with threonineserine kinase activity. Genes from neighboring loci (19p13.3 and 13.4) could also be involved.

Diagnostic criteria include hamartoma-like intestinal polyposis, melanin deposits responsible for oral lentiginosis and a family history.

Skin involvement presents as lentigines which appear most often in the first months of life, usually before the age of 2 years. They are constantly localized on the lips and in $80 \%$ of cases, on the oral mucosa (inner surface of the lips and cheeks, gums, palate). The tongue is only exceptionally affected.

Gastrointestinal manifestations presented by hamartomatous polyps. The most common location is the small intestine, stomach, and colon. Other locations are possible in the pelvis, lungs and bladder. Polyps appear in young age and become symptomatic between 10 and 30 years. When they appear early, they are responsible for the clinical signs: chronic abdominal pain (23\%), digestive haemorrhages (rectal bleeding, anemia 14\%), rectal prolapse (7\%), intestinal obstruction $(43 \%) .^{5}$ They are generally pedicled, except in the stomach, where they are sessile. They number 10 to 20 per segment of the intestinal tract and vary in size from 0.1 to $5 \mathrm{~cm}$ in diameter. ${ }^{6}$

There is no link between polyp size and degenerative potential and only $2 / 75$ polyps can degenerate. ${ }^{7}$ The pediatric forms do not present any clinical particularity compared to the adult forms. ${ }^{3}$ Peutzjeghers syndrome is associated with an increased risk of developing early (before the age of 40) a malignant tumor, especially of the small intestine, compared to the general population. The frequently organs affected are the gastrointestinal tract (esophagus, stomach, small intestine, colon, rectum and pancreas) ${ }^{4}$ lung $^{8}$ prostate, breast ${ }^{9}$ and reproductive organs. ${ }^{4,10}$ Faced with this high risk of intra- and extra- digestive malignant degeneration, peutz- jeghers syndrome requires close and long-term monitoring, responding to a well-codified periodicity. Treatment should be conservative whenever possible, to avoid repeated bowel resections, and preserve the digestive tract, especially in children who are still growing.

The monitoring cycle consists of endoscopy every 2 years and removal of polyps for the asymptomatic patients. Magnetic resonance imaging is the test of choice for monitoring the small intestine and testes. For women's, mammography, pap smear, and endovaginal ultrasound must be done every 1 to 2years. Occlusive episodes secondary to polyps are self-limiting in children, so polypectomy is not systematic. Also monitoring of the blood count to detect anemia secondary to bleeding. ${ }^{4,7}$ There is no standardized treatment for skin and mucous membrane pigmentation, the treatment involves cryosurgery, dermabrasion and Q-switched laser. ${ }^{4}$

\section{Conclusion}

Peutz-jeghers syndrome is a rare genetic entity with autosomal dominant inheritance, characterized by the association of cutaneousmucous lentiginosis and gastrointestinal hamartomatous polyps with an increased risk of degeneration requiring regular periodic and longterm monitoring.

\section{Acknowledgments}

None.

\section{Conflicts of interest}

The authors declare that there are no conflicts of interest.

\section{Funding}

None.

\section{References}

1. McGarrity TJ, Amos C. Peutz-Jeghers syndrome: Clinicopathology and molecular alterations. Cell Mol Life Sci. 2006;63(18):2135-2144.

2. Heymann WR. Peutz-Jeghers syndrome. J Am Acad Dermatol. 2007;57:513-514

3. Tovar JA, Eizaguirre I, Albert A, et al. Peutz-Jeghers Syndrome in Children: Report of Two Cases and Review of the Literature. $J$ Pediatr Surg. 1983;18(1):1-6.

4. Higham P, Alawi F, Stoopler ET. Medical management update: Peutz Jeghers syndrome. Oral Surg Oral Med Oral Pathol Oral Radiol Endod. 2010;109(1):5-11.

5. Benamouzig R, Chaussade S, Olschwang S. Polyposis coli: a practical approach. Gastroenterol Clin Biol. 2005;29(10):1035-1039.

6. Peutz JLA. Very remarkable case of familial polyposis of mucous membrane of intestinal tract and nasopharynx accompanied by peculiar pigmentations of skin and mucous membrane. Nederl Maandische Geneesk. 1921.

7. Cherki S, Adham M, Bizollon T. Intussusception in Peutz-Jeghers syndrome and review of the literature. Annals of Surgery. 2002;127:714 717.

8. von Herbay A, Arens N, Friedl W. Bronchioloalveolar carcinoma: a new cancer in Peutz-Jeghers syndrome. Lung Cancer. 2005;47(2):283-288.

9. Conneely JB, Kell MR, Boran S. A case of bilateral breast cancer with Peutz' Jeghers syndrome. Eur J Surg Oncol. 2006;32(1):121-122.

10. Chen KT. Female genital tract tumors in peutz-jeghers syndrome. Hum Pathol. 1986;17(8):858-861. 